This item was submitted to Loughborough's Research Repository by the author.

Items in Figshare are protected by copyright, with all rights reserved, unless otherwise indicated.

\title{
Anti-social behaviour legislation and the policing of boy racers: dispersal orders and seizure of vehicles
}

PLEASE CITE THE PUBLISHED VERSION

http://dx.doi.org/10.1093/police/pau005

\section{PUBLISHER}

Oxford University Press / ( ) The Author.

VERSION

AM (Accepted Manuscript)

\section{PUBLISHER STATEMENT}

This work is made available according to the conditions of the Creative Commons Attribution-NonCommercialNoDerivatives 4.0 International (CC BY-NC-ND 4.0) licence. Full details of this licence are available at: https://creativecommons.org/licenses/by-nc-nd/4.0/

\section{LICENCE}

CC BY-NC-ND 4.0

\section{REPOSITORY RECORD}

Lumsden, Karen. 2019. "Anti-social Behaviour Legislation and the Policing of Boy Racers: Dispersal Orders and Seizure of Vehicles". figshare. https://hdl.handle.net/2134/16359. 
This is a pre-publication version of Lumsden, K. (2013) 'Anti-Social Behaviour Legislation and the Policing of Boy Racers: Dispersal Orders and Seizure of Vehicles’, Policing: a Journal of Policy and Practice. Online first. DOI 10.1093/police.pau005

Anti-Social Behaviour Legislation and the Policing of Boy Racers: Dispersal Orders and Seizure of Vehicles

\title{
Dr Karen Lumsden, Department of Social Sciences, Loughborough University, UK
}

\begin{abstract}
This paper considers the policing of young drivers in Scotland who are known as boy racers. It outlines the ways in which the police addressed the problem of anti-social driving by youths in a built-up urban environment in the context of concern and pressure from businesses, residents, the local authority, media and government. Policing practices were shaped by the introduction of anti-social behaviour legislation including dispersal orders and seizure of vehicles. This involved behaviours not previously seen as deviant or anti-social now being defined as such, in relation to the perceptions of local residents and businesses. The paper considers the success of the use of anti-social behaviour legislation, including dispersal orders and seizure of vehicles, and the impact this had on police relations with young drivers.
\end{abstract}

\section{Introduction: Policing the Roads}

As an area of academic and practitioner analysis and debate, roads policing has largely remained under the radar, despite the fact that the vast majority of citizens' experiences of police occur in the context of driving on the public highways (for exceptions see Corbett, 2003, 2008; Waddington, 2010; Wells, 2008). As Corbett (2008: 131) notes, roads policing is the 'public face' of the police for many citizens. This form of policing draws police officers into interactions with individuals who may not otherwise come under the scrutiny of the authorities (Schafer and Mastrofski, 2005). Becker (1963) argues that we do not think of the 
This is a pre-publication version of Lumsden, K. (2013) 'Anti-Social Behaviour Legislation and the Policing of Boy Racers: Dispersal Orders and Seizure of Vehicles', Policing: a Journal of Policy and Practice. Online first. DOI 10.1093/police.pau005

person who commits a traffic offence as different from the rest of us and thus their infraction is treated tolerantly. This is despite research that demonstrates the links between individuals' engagements in minor and major road traffic offending and mainstream crime (Corbett, 2008; see also Chenery et al. 1999; Rose, 2000).

Police interactions and engagement with young and/or inexperienced motorists requires further analysis, particularly in relation to the outcomes and measurement of the success of various educational road safety initiatives which are delivered by police forces across the United Kingdom as a means of addressing high numbers of road traffic fatalities and collisions involving young drivers. Research has demonstrated that males are more likely to be on the roads, often due to socio-cultural reasons, as well as having a greater propensity to take risks, compared to females (Toroyan and Peden, 2007). The socio-economic background of a family also affects the likelihood of a child or young person being killed or injured in a road traffic collision, with those from economically poor backgrounds at a greater risk (Toroyan and Peden, 2007). Late night driving is also said to be a predictive factor for serious crashes among young drivers (Peden et al. 2004: 79). Factors behind the elevated risks include mobility patterns and vehicle characteristics (for instance the vehicle is often borrowed); psychological characteristics, such as thrill-seeking and over-confidence; lower tolerance of alcohol compared with older people; and excess or inappropriate speed, the most common error among young drivers and riders (Peden et al. 2004: 79). In the United Kingdom, attempts to address driver inexperience include the introduction of the British Driving Standards Agency (DSA) 'Pass Plus Driving Scheme' which is geared towards those motorists who have passed their driving test within the last two years and, as such, are claimed to be more likely to have an accident during this period due to lack of driving experience (Directgov, 2010). Further courses are offered in the form of the 'Advanced 
This is a pre-publication version of Lumsden, K. (2013) 'Anti-Social Behaviour Legislation and the Policing of Boy Racers: Dispersal Orders and Seizure of Vehicles', Policing: a Journal of Policy and Practice. Online first. DOI 10.1093/police.pau005

Driving Test'. However, these efforts to address driver inexperience are voluntary and thus not taken up by those motorists who would most benefit from changes in driving behaviours. In addition, the Road Traffic (New Drivers) Act 1995 was introduced in order to address the problem of driver inexperience. The Act requires newly qualified drivers to retake the driving test if they acquire six penalty points or more within two years of passing their test.

Road traffic collisions and fatalities involving young people continually prompt media, police, government and road safety charity campaigns designed to warn and (re)educate young drivers on the importance of road safety (Author, 2013a). However there is also a tendency for media representations of car modifiers or the stereotypical boy racer to conflate this with the problem of risky driving by youths or uneducated drivers (Author, 2013b). This has repercussions for roads policing. This includes officers' definitions and judgements of driver deviance in relation to motorists who own/drive a modified car, and those individuals driving a non-modified car who may still be flouting road traffic legislation nonetheless. This paper considers the practical aspects of policing the roads in the context of young drivers, known as boy racers, in Aberdeen, Scotland ${ }^{1}$ by focusing specifically on the use of anti-social behaviour legislation (including dispersal orders and seizure of vehicles) and the impact this had on police relations with the young drivers. The use of these powers was successful in temporarily dispersing drivers from the beach area of the city in the short term, thus providing respite to local residents who were concerned about anti-social driving, but in the longer term risked stigmatizing and marginalizing young drivers further and thus impacting negatively on police-driver relations in the context of public perceptions of roads policing.

Hence, this discussion highlights the double-edged nature of anti-social behaviour management and enforcement interventions engaged in by police. There is a tension between 
This is a pre-publication version of Lumsden, K. (2013) 'Anti-Social Behaviour Legislation and the Policing of Boy Racers: Dispersal Orders and Seizure of Vehicles', Policing: a Journal of Policy and Practice. Online first. DOI 10.1093/police.pau005

the successful consensual management of younger drivers - boy racers - and the enforcement-led approaches reflected in the use of anti-social behaviour legislation (including seizure of vehicles and dispersal orders), which risk marginalizing and ostracizing youth groups further and setting up more confrontational relations between young people and the police.

The next section outlines the background and history to Aberdeen's boy racer culture. The discussion then turns to the introduction of anti-social behaviour legislation in the United Kingdom and Scotland, before considering the use of dispersal orders and seizure of vehicles to police Aberdeen's boy racers and the success of these measures.

\section{Boy Racers in Aberdeen, Scotland}

Boy racers (or 'Bouley Bashers’ as they are known locally) have frequented Aberdeen’s Beach Boulevard road since its construction in the late 1960s. The road and an adjacent area used to park cars (known as the 'trammers ${ }^{2}$ ) are frequented by young drivers who travel into the city from surrounding towns and villages. This particular urban space has functioned as a forum for youths to display their cars and modifications, driving skills, and socialise with like-minded car enthusiasts. However, urban regeneration from the 1990s onwards introduced a middle-class impetus concerned with cleansing the area of boy racers. This included new residential developments, leisure facilities, and retail outlets. The result was increased moral contestation and debate from local residents and businesses calling for action from police, politicians and the local authority, to oust the boy racers from this particular public space. Residents complained that drivers were engaging in deviant and/or anti-social behaviour including speeding, illegal street racing, revving engines, loud music from car stereo systems, 
This is a pre-publication version of Lumsden, K. (2013) 'Anti-Social Behaviour Legislation and the Policing of Boy Racers: Dispersal Orders and Seizure of Vehicles', Policing: a Journal of Policy and Practice. Online first. DOI 10.1093/police.pau005

littering, gathering in large groups and urinating in public, According to local newspaper, the

Press \& Journal (2003: 15):

Boy racers are not a new phenomenon; they have been a serious irritant for a number of years, particularly to those who are unfortunate enough to cross their paths. However in today's affluent society, there just happens to be more of them. This is particularly so in Aberdeen, where the 'Bouley Boys' have traditionally screeched around the Beach Boulevard area with apparent impunity while any restrictions imposed on them have had only limited success. Long-suffering local people have reached the end of their tether, so police have announced a three-day crackdown. The only problem with three-day crackdowns is that they only last three days... The police and local authority need to remove this blight from the beach area once and for all by rooting out the hard-core troublemakers... Councillors appear to shrug their shoulders as if they have done enough; this is not an option. Efforts should be redoubled to solve the problem before the boy racers start driving something new; that is, driving visitors and businesses away from the beach area.

For the police, previous containment of the young drivers in this area of the city was no longer a viable long-term solution. There were a host of options that police had available to them which included road traffic operations, community policing (which incorporated regular meetings between officers and drivers at what became known as the Grampian Police 'Drivers' Group'), a proposal to close the Beach Boulevard road each evening with access to residents only, and the use of road traffic and anti-social behaviour legislation. The myriad internal and external pressures that the police were faced with and thus had to negotiate in the course of their policing activities and practices are reflected on elsewhere (see Author, 2013c). The discussion which follows focuses specifically on the use of anti-social behaviour legislation (including dispersal orders and seizure of vehicles powers) and its success in terms of regulating and deterring deviant driving and anti-social behaviour at Aberdeen's seafront.

\section{Methods}

The discussion is based on doctoral research conducted between 2005 and 2008 in Aberdeen,

Scotland. It focused on the internal dynamics and practices of the boy racer culture, and the 
This is a pre-publication version of Lumsden, K. (2013) 'Anti-Social Behaviour Legislation and the Policing of Boy Racers: Dispersal Orders and Seizure of Vehicles', Policing: a Journal of Policy and Practice. Online first. DOI 10.1093/police.pau005

societal reaction to the group on the part of the local community, police, media, and local and government. In the former case, 150 hours of participant observation was conducted with the drivers at Aberdeen's Beach Boulevard and in various other locations across Scotland. This included eight interviews with drivers ${ }^{3}$ and informal interviews conducted during the course of the fieldwork. In order to investigate the societal reaction interviews were conducted with five police officers, two journalists, three local politicians, two residents, and a group interview with four residents present. Over 250 local newspaper reports which focused on Aberdeen's boy racers were also analysed, in addition to relevant police, council and governmental reports. I also attended a formal community meeting where local residents, police, politicians, council officials and business representatives discussed the problem of boy racers, a formal council meeting, and a road safety event organised by Grampian Police. Police and drivers interactions were also observed at a series of Grampian Police 'Drivers' Group’ meetings, which were held approximately every three-months and were attended by a Neighbourhood Officer and five drivers. Although the Neighbourhood Officer and a representative from the drivers recorded minutes of these meetings, they were generally informal in nature and took place in a café adjacent to the Beach Boulevard in the evenings. The remainder of the paper considers the use of anti-social behaviour legislation to regulate the behaviour of young drivers.

\section{Anti-Social Behaviour Legislation and Aberdeen's Boy Racers}

Given its devolved status in matters of law and order, Scotland has its own separate Act in which anti-social behaviour powers are enshrined - the Antisocial Behaviour (Scotland) Act (2004). ${ }^{4}$ The Act reflects a recurrent theme which lay at the heart of New Labour's law and order agenda from their election in 1997 - the drive to be 'tough on crime, tough on the causes of crime' (Bannister et al. 2006). While in power, New Labour introduced a huge 
This is a pre-publication version of Lumsden, K. (2013) 'Anti-Social Behaviour Legislation and the Policing of Boy Racers: Dispersal Orders and Seizure of Vehicles', Policing: a Journal of Policy and Practice. Online first. DOI 10.1093/police.pau005

array of crime-related legislation. According to one estimate, between 1997 and 2008, Labour created more than 3,000 new criminal offences (Loader 2008), with nearly 50 acts of parliament passed relating to crime, disorder, policing, criminal justice and punishment between 1997 and 2006 (Emmerson and Frayne, 2005). Hence, police forces now had at their disposal a raft of powers through which to address minor incivilities. This is in the context of increased political impetus towards tackling anti-social behaviour and public awareness via media exposure in the form of reports of wide-ranging and often bizarre behaviours that were defined as ‘anti-social’ and thus criminalized.

\section{Dispersal Orders}

In March 2005, Section 3 of the Antisocial Behaviour (Scotland) Act (2004), Dispersal of Groups, was applied to the beach area of Aberdeen for a three-month period, between the hours of 8pm and 6am. ${ }^{5}$ It was renewed again on 31 May 2005 for an additional threemonths. ${ }^{6}$ Dispersal of Groups gave a senior police officer the power to 'designate an area’ (in this instance the Beach Boulevard) in consultation with the local authority, where significant, persistent and serious anti-social behaviour had occurred and the presence of behaviour or groups was contributing to the problem. Before a senior officer designated an area, an authorization notice specifying the designated locality and date when the designation would begin and end was drawn up. In the designated area the police had the power to disperse groups of two or more individuals if their presence or behaviour was causing, or was likely to cause, alarm or distress to any member of the public. The police could require any person who did not live in the area to leave and could prohibit them from returning to the area for the next 24 hours. Failure to do so could result in a $£ 2,500$ fine or three-month prison sentence. In an authorization notice warning of the implementation of the dispersal order, the Chief Superintendent of Grampian Police stated: 
This is a pre-publication version of Lumsden, K. (2013) 'Anti-Social Behaviour Legislation and the Policing of Boy Racers: Dispersal Orders and Seizure of Vehicles', Policing: a Journal of Policy and Practice. Online first. DOI 10.1093/police.pau005

I have reasonable grounds for believing that members of the public have been alarmed or distressed as a result of the presence or behaviour of groups of two or more persons in public places, and that antisocial behaviour is a significant, persistent and serious problem, in the relevant locality specified. (Evening Express, 2005: 3)

It was further claimed that:

Due to the numbers of racers involved and the nature of the issues, it was generally inappropriate to use Seizure of Vehicles legislation. Off road driving was not an issue and detection of careless driving was difficult due to the road layout. In addition to the driving problems, the racers were gathering in groups with their cars, and causing alarm and distress to members of the public in the same area. It was therefore felt that the power to disperse these groups would have a knock on effect on the driving. (Antisocial Behaviour Scotland, 2007)

Grampian Police were the only authority in Scotland to use a dispersal order in relation to boy racers, with two dispersal notices issued between March 2005 and August 2005 for Aberdeen’s Beach area (Scottish Government, 2007). The dispersal order was only to be used for a short period to provide respite to local residents. Therefore, on 28 August 2005 Grampian Police elected not to renew the dispersal powers for a third time claiming that:

The reduction in reported incidents is very encouraging and the responsible drivers should be commended for their attempts at self-regulation... I do not believe the power is intended to be used repeatedly over extended periods without giving those who have been involved in antisocial behaviour the opportunity to show they can amend their ways voluntarily. (Lawther, 2005: 2)

From implementation of the dispersal order in March 2005, a total of 71 drivers were dispersed from the area. Two men (a driver and his passenger) were charged of breaching an order to disperse and after several adjournments were found guilty of an offence under Section 22 of the Act. According to newspaper reports they were banned from returning to the area for 24 hours, but 'decided to make a point' by going back a few hours later (Marshall, 2007: 1). Their appeal was admonished at Aberdeen Sheriff Court in December 2006, however one of the men voiced plans to take his case to the European Court of Human Rights 
This is a pre-publication version of Lumsden, K. (2013) 'Anti-Social Behaviour Legislation and the Policing of Boy Racers: Dispersal Orders and Seizure of Vehicles', Policing: a Journal of Policy and Practice. Online first. DOI 10.1093/police.pau005

in Strasbourg. This was the first case of its kind in Scotland under the new anti-social behaviour legislation.

The justification for use of the dispersal order was that it would provide respite to local residents who were tired of the night-time antics of boy racers. Police and residents reported that the dispersal order had been successful in deterring drivers from Aberdeen's seafront. However, the implementation of anti-social behaviour powers was also a means of tempering community concern and being seen to act, and in the wider political context of pressure from the Scottish Executive to implement these new powers. For instance, an officer highlighted the problem in determining whether action was necessary in relation to residents' perceptions of speed and anti-social behaviour:

...They think they must be speeding but because of the noise that some of these exhausts make. They can be travelling at $30 \mathrm{mph}$ and the noise is just horrendous from the exhaust. The other kind of problems are the continual parking up at night-time at sides of the road where it's illegal to park and you get them congregating - starting off with four cars, anything up to 20 cars and obviously there's a number of people come out of the cars... There could be three people in each car. So you've then got 20 cars, 60 people gathered just in a street and they all tend to get out and go to the centre car or centre area and again the look of that... 60 folk gathering is suddenly, 'Ooh'. You know, it's a bit daunting for folk to approach even though they're not doing anything at all. They're just gathering there chatting. They're having a laugh but then that causes noise. That causes the thought again if you happen to be at the window and you're seeing them you think, 'Oh God, what's going on there?' (Interview with Neighbourhood Officer, May 2005)

As noted previously, the way that police used these powers was of interest to the media, with stories of anti-social behaviour high on their reporting agenda. Figures obtained under a Freedom of Information Act request by the Evening Express also showed that of the 562 complaints made to the police between 2003 and 2005, 145 came from the same three residents (Ewen, 2006: 10). There was also an increase in complaints in 2005 when the dispersal order was in effect. Police, politicians and the local authority all reported that the 
This is a pre-publication version of Lumsden, K. (2013) 'Anti-Social Behaviour Legislation and the Policing of Boy Racers: Dispersal Orders and Seizure of Vehicles', Policing: a Journal of Policy and Practice. Online first. DOI 10.1093/police.pau005

dispersal order had been successful; however residents continued to complain while the order was in place and despite greater police presence at the Beach Boulevard.

\section{Seizure of Vehicles}

Seizure of vehicles powers were introduced in Scotland in 2005 and gave police the power to seize a vehicle if used in a way that caused alarm, distress or annoyance to the public on or off-road. In the Grampian area 814 warnings were issued and 83 cars seized between 1 October 2004 and 31 March 2007 (Scottish Government, 2007). Part One of the Road Traffic Act 1988 states that any person who 'drives a motor vehicle on a road recklessly is guilty of an offence' and that 'if a person drives a motor vehicle on a road without due care and attention, or without reasonable consideration for other persons using the road, he is guilty of an offence'. However this legislation applies only to the motorist. In contrast, the seizure of vehicles power targeted both the driver of the vehicle and the vehicle itself. If a vehicle was driven in a way which caused alarm or distress to members of the public, police could issue the driver of the vehicle with a warning. If the driver did the same a second time, then the car could be seized and impounded by police. The difference with this legislation rests on the fact that if the same car was driven in an anti-social manner by another motorist, police could still seize the vehicle. If the motorist who received the warning did the same a second time in a different vehicle, then the warning also still applied.

Seizure of vehicles powers helped officers to address the illegal modifications which youths carried out in efforts to personalize their vehicles. Car modification was a central ritual of the subculture and the Beach Boulevard was a forum in which the youths exhibited their cars and sought admiration from their peers. When asked directly about seizure of vehicles, a police officer explained: 
This is a pre-publication version of Lumsden, K. (2013) 'Anti-Social Behaviour Legislation and the Policing of Boy Racers: Dispersal Orders and Seizure of Vehicles', Policing: a Journal of Policy and Practice. Online first. DOI 10.1093/police.pau005

They're given one chance. If I go down, for example, and they're playing loud music or they're revving their engine or if they're sitting at lights, skirl the wheels, and take off at the lights, then I stop them. They're given an official warning under the terms of the anti-social behaviour legislation. The warning is then recorded on a national computer. They're also sent out a letter by the Antisocial Behaviour Unit saying: 'You've been warned. If you get another warning, i.e. if you're stopped again we'll seizure your vehicle'... It's a different way of thinking rather than just reporting it to the [Procurator] Fiscal. It takes months to report something and the Fiscal might not take any proceedings at the end of the day. It's unusual but that can happen. This way you're stopping them at the time. They're being told don't do it again. If they do it again they're well aware that they've been warned and we'll take their vehicle and I think that has a more profound effect because you're stopping them at the time of the offence... (Interview with Officer 4, Antisocial Behaviour Unit, August 2006)

This police officer believed that anti-social behaviour legislation was more effective since police were able to deal with offenders on the spot rather than relying on the perceived inefficiency of the criminal justice system. Moreover, the mobility the car afforded its user was challenged through its immediate removal. Seizure of vehicles also enabled patrol officers to police the roads:

I'm specially trained to do a whole lot of things like examine vehicles, drive highperformance cars, driver high-performance bikes, vehicle crash investigation. There are all these kinds of specialities within the traffic, but because of the Antisocial Behaviour (Scotland) Act 2004 normal police, beat cops, can go down and enforce legislation because there's a tendency for a lot of people within the police not to deal with traffic stuff because it can be quite complex. But once you get to have an interest in vehicles then it does help and for that reason a lot of people shy away from basically dealing with road traffic legislation. But with the anti-social behaviour stuff it's easier for them to get in about. (Interview with Officer 2, Roads Policing, October 2006)

Therefore, officers highlighted the benefit of anti-social behaviour powers such as seizure of vehicles in that they allowed officers to address inappropriate or risky driving behaviours by youths at Aberdeen's Beach Boulevard, without having the specific required expert training of Traffic Officers. Thus officers could seize vehicles if, for instance, drivers were uninsured, had not paid their road tax, were driving in a style deemed dangerous or 'anti-social', for 
This is a pre-publication version of Lumsden, K. (2013) 'Anti-Social Behaviour Legislation and the Policing of Boy Racers: Dispersal Orders and Seizure of Vehicles', Policing: a Journal of Policy and Practice. Online first. DOI 10.1093/police.pau005

noise pollution related to loud exhausts, music, or revving engines, or if car modifications (such as window tints) contravened road traffic legislation.

\section{Discussion}

This paper focused on the use of anti-social behaviour legislation (including dispersal orders and seizure of vehicles powers_by police to tackle boy racers in the city of Aberdeen, Scotland. Although the use of these powers were effective in the short-term in terms of deterring drivers from this public space and providing respite to the residents, they raise a host of issues in relation to the use of anti-social behaviour powers to police the roads. As McGarry (2011) notes, police now have more power to take action against both serious or criminal terrorist activity and low-level offences. In the case of Aberdeen's boy racers, behaviours, which were before deemed acceptable and legal, were now labelled as deviant and/or anti-social as a result of the introduction and use of anti-social behaviour legislation. The redefinition of certain minor incivilities as anti-social resulted in a plethora of driving activities, behaviours and rituals becoming punishable by the police in relation to the use of ASBOs, dispersal orders, and seizure of vehicle powers. Moreover, what exactly constitutes anti-social behaviour is contextual and situationally specific, and seen through the 'eyes of the beholder'. As Millie (2008: 383) argues, the perception of anti-social is strongly influenced by sensory or aesthetic cues, and has the potential to lead to the labelling of all young people in a group as anti-social. In this case, sensory and aesthetic cues included the modified car, loud exhausts and stereo systems, revving engines, and car headlights. Hence, police must take account of this when deciding to act on complaints from citizens and concerned motorists in relation to problematic driving. 
This is a pre-publication version of Lumsden, K. (2013) 'Anti-Social Behaviour Legislation and the Policing of Boy Racers: Dispersal Orders and Seizure of Vehicles', Policing: a Journal of Policy and Practice. Online first. DOI 10.1093/police.pau005

The use of these powers was successful in the short term as they helped to temporarily disperse drivers from the beach area of the city, thus providing respite to local residents who were concerned about anti-social behaviour and dangerous driving. Therefore, the introduction of anti-social behaviour legislation had an impact on the policing of Aberdeen's Beach Boulevard. This included shaping relations between police officers and drivers. Officers highlighted the merits of dispersal orders and seizure of vehicles powers in terms of dispersing drivers from this area of the city, and aiding officers in policing the roads via the use of seizure of vehicles, and in dealing with traffic offenders 'on the spot'.

However, in the longer term the use of anti-social behaviour legislation risked stigmatizing and marginalizing young drivers further and thus impacting negatively on police-driver relations in the context of public perceptions of roads policing. Drivers highlighted perceived inconsistencies in how traffic officers, patrol officers, and anti-social behaviour officers interacted with them. For instance:

Craig told us that recently he'd been stopped by police at the beach and fined because of the tints on his windows but someone else he knew had been fined more and got points on his licence. The police officer told him that the reason for this is the level of tint and whether or not it is dangerous for driving. He told Craig that these powers had been available to the police for three years and it's only now that they've decided to enforce them in Aberdeen. Other parts of the country have been doing it for a while now. (Fieldnotes, December 2006)

The ad hoc way in which they felt these powers were used from driver-to-driver, and the situational and context specificity of what constitutes 'anti-social' behaviour, resulted in confusion for drivers who wished to comply with the law. In addition, as noted above, the dispersal order could not be sustained in the long term and once it ended drivers returned to the Beach Boulevard as before. Hence, a more joined-up approach between traffic, patrol officers and anti-social behaviour officers is needed, as is more police interaction and 
This is a pre-publication version of Lumsden, K. (2013) 'Anti-Social Behaviour Legislation and the Policing of Boy Racers: Dispersal Orders and Seizure of Vehicles', Policing: a Journal of Policy and Practice. Online first. DOI 10.1093/police.pau005

education with young motorists, particularly in relation to the shifting requirements for road traffic safety and car modifications, which many car enthusiasts/modifiers may not have knowledge of.

Finally, more analysis and reflection is needed with regards to the ways in which anti-social behaviour legislation is being used to police the roads, in contrast and addition to the use of road traffic legislation. This specifically includes the use of seizure of vehicles powers. Evidence-based roads policing of this nature could help contribute to public reassurance, particularly in the context of the widening use of various surveillance technologies or 'techno-fixes' (Wells, 2008) such as speed cameras and automatic number plate recognition (ANPR), which Corbett (2008) points out are in danger of further alienating motorists from support for roads policing and the implementation of related surveillance technologies.

\section{References}

Antisocial Behaviour Act. (2003), London: The Stationary Office Ltd.

Antisocial Behaviour (Scotland) Act. (2004), London: The Stationary Office Ltd.

Antisocial Behaviour Scotland (2007), Aberdeen Dispersal, Online. Available at: http://www.antisocialbehaviourscotland.com (accessed January 2009).

Author (2013a), 'Anonymised for Peer Review’.

Author (2013b) ‘Anonymised for Peer Review’.

Author (2013c) ‘Anonymised for Peer Review’.

Bannister, J., Fyfe, N. and Kearns, A. (2006) 'Respectable or Respectful? (In)civility and the City’, Urban Studies, 43(5): 919—37.

Becker, H.S. (1963), Outsiders, New York: Free Press. 
This is a pre-publication version of Lumsden, K. (2013) 'Anti-Social Behaviour Legislation and the Policing of Boy Racers: Dispersal Orders and Seizure of Vehicles', Policing: a Journal of Policy and Practice. Online first. DOI 10.1093/police.pau005

Chenery, S., Henshaw, C. and Pease, K. (1999), Illegal Parking in Disabled Bays: A Means of Offender Targeting, Briefing Note 1/99, HORS, London: Home Office.

Corbett, C. (2003), Car Crime, Devon: Willan Publishing.

Corbett, C. (2008), 'Roads Policing: Current Context and Imminent Dangers’, Policing, 2(1): $131-42$.

Crime and Disorder Act (1998), London: The Stationary Office Ltd.

Directgov (2010) Pass Plus Scheme for Car Drivers. Online. Available at: http://www.direct.gov.uk/en/Motoring/LearnerAndNewDrivers/Passplusdrivingcoursefornew drivers/DG_4022426 (accessed September 2012).

Donnelly, D. and Scott, K. (2008), 'Policing in Scotland', in T. Newburn (ed.) Handbook of Policing, 2nd edn, Devon: Willan Publishing, pp.182—203.

Emmerson, C. and Frayne, C. (2005) Public Spending, Election Briefing 2005, London: Institute for Fiscal Studies.

Evening Express (2005), 'Authorization notice’, 1 March 2005, p.3.

Ewen, D. (2006), ‘Three Residents Clock Up 145 Bouley Complaints', Evening Express (28 February 2006, p.10).

Lawther, G. (2005), ‘Scaling down of boulevard battle’, Evening Express, 29 August 2005, p.2.

Loader, I. (2008), 'The Great Victim of this Get-Tough Hyperactivity is Labour', The Guardian, 19 June $2008 . \quad$ Online. Available at: http://www.theguardian.com/commentisfree/2008/jun/19/justice.ukcrime (accessed November 2013).

Marshall, C. (2007), 'McConnell confronted as he hails action on rowdies', Press and Journal, 12 April 2007, p.1.

McGarry, J. (2011), 'Named, Shamed and Defamed by the Police’, Policing, 5(3): 219—27. 
This is a pre-publication version of Lumsden, K. (2013) 'Anti-Social Behaviour Legislation and the Policing of Boy Racers: Dispersal Orders and Seizure of Vehicles', Policing: a Journal of Policy and Practice. Online first. DOI 10.1093/police.pau005

Millie, A. (2008), 'Anti-social Behaviour, Behavioural Expectations and an Urban Aesthetic', British Journal of Criminology, 48: 379—94.

Peden, M., Scurfield, R., Sleet, D., Mohan, D., Hyder, A.A., Jarawan, E. and Mathers, C. (eds), (2004), World Report on Road Traffic Injury Prevention, Geneva: World Health Organization.

Press \& Journal (2003), ‘Solving the Boy Racer Problem’, (25 July 2003, p.15).

Rose, G. (2000), The Criminal Histories of Serious Traffic Offenders, HORS 206, London: Home Office.

Schafer, J.A., and Mastrofski, S.D. (2005), 'Police Leniency in Traffic Enforcement Encounters: Exploratory Findings from Observations and Interviews', Journal of Criminal Justice, 33: 225-38.

Scottish Government (2007), Community Safety and Antisocial Behaviour Policy Update: Summer 2007, Online. Available at: http://www.antisocialbehaviourscotland.com> (accessed October 2008).

Toroyan, T. and Peden, M. (eds), (2007), Youth and Road Safety, Geneva: World Health Organization.

Waddington, P.A.J. (2010), 'Police Pursuits: A Case Study of “Critical Friendship”?' Policing, 4(2): 119—26.

Wells, H. (2008), 'The Techno-Fix Versus the Fair Cop: Procedural (In)justice and Automated Speed Limit Enforcement', British Journal of Criminology, 48: 798—817.

\footnotetext{
${ }^{1}$ There are substantial differences and similarities between policing in Scotland and the rest of the UK. Scottish policing shares certain principles and strategies with the UK such as policing by consent and the tripartite system (consisting of police authorities, chief constables and the government). Differences can be found in Scots law, legal systems and historical traditions such as community policing. Scottish devolution had a considerable impact on policing since 1999, with changes instigated from the government, policy makers, working groups and police organisations (Donnelly and Scott, 2008). Moreover, in March 2013 Scotland's eight police forces were merged into one single force: 'Police Scotland'.
} 
This is a pre-publication version of Lumsden, K. (2013) 'Anti-Social Behaviour Legislation and the Policing of Boy Racers: Dispersal Orders and Seizure of Vehicles’, Policing: a Journal of Policy and Practice. Online first. DOI 10.1093/police.pau005

\footnotetext{
${ }^{2}$ The 'trammers' are an area adjacent to the Beach Boulevard road and facing the seafront where the last remnants of Aberdeen's tramlines lie. Drivers use this area to park up their cars and socialise with one another.

${ }^{3}$ The identities of respondents have been anonymised.

${ }^{44}$ In England and Wales these powers were originally enshrined in the Crime and Disorder Act 1998 and then subsequently the Antisocial Behaviour Act 2003.

${ }^{5}$ Although this marks the first official legislative use of a dispersal order as a policing tool, attempts were previously made to disperse the drivers via other means such as police operations and urban regeneration strategies (particularly through redesigning the road layout).

${ }^{6}$ An area can be designated for up to but no longer than three-months.
} 